\title{
An N-linked High-mannose Type Oligosaccharide, Expressed at the Major Outer Membrane Protein of Chlamydia trachomatis, Mediates Attachment and Infectivity of the Microorganism to HeLa Cells
}

\author{
Cho-chou Kuo, ${ }^{*}$ Noriko Takahashi, ${ }^{\S}$ Albertina F. Swanson, ${ }^{\star}$ Yasuhiro Ozeki, ${ }^{\ddagger}$ and Sen-itiroh Hakomori ${ }^{\star \ddagger}$ \\ *Department of Pathobiology, University of Washington, Seattle, Washington 98195; ${ }^{*}$ Biomembrane Institute, Seattle, Washington 98119; \\ and ${ }^{\S}$ The Glyco-Lab, Central Research Institute, Nakano Vinegar Co., Handa, 475 Japan
}

\begin{abstract}
The structure of the carbohydrate of the $40-\mathrm{kD}$ major outer membrane component of Chlamydia trachomatis and its role in defining infectivity of the organism were investigated. The oligosaccharides were released from the glycoprotein by $\mathrm{N}$-glycanase digestion, coupled to a 2 -aminopyridyl residue, and subjected to two-dimensional sugar mapping technique. The major fractions consisted of "highmannose type" oligosaccharides containing 8-9 mannose residues. Bi- and tri-antennary "complex type" oligosaccharides having terminal galactose were detected as minor components. These oligosaccharides were $\mathrm{N}$-linked and contained no sialic acid. This structural profile is consistent with our previous characterization based on lectin-binding and glycosidase digestion. Functional specificity of identified chlamydial oligosaccharides was analyzed using glycopeptides fractionated from ovalbumin and structurally defined oligosaccharides from other sources. The glycopeptide fraction having high-mannose type oligosaccharide, as compared to those having complex or hybrid-type, showed a stronger inhibitory effect on attachment and infectivity of chlamydial organisms to HeLa cells. Among high-mannose type oligosaccharides, the strongest inhibition was observed with mannose 8 as compared with mannose 6,7 , or 9 . These results indicate that a specific high-mannose type oligosaccharide linked to the major outer membrane protein of $C$. trachomatis mediates attachment and infectivity of the organism to HeLa cells. (J. Clin. Invest. 1996. 98:2813-2818.) Key words: bacterial glycoprotein $\bullet$ carbohydrate $\bullet$ ligand • intracellular organism $\bullet$ parasite-host cell interaction
\end{abstract}

\section{Introduction}

Chlamydia trachomatis is one of the most common causes of blindness and sexually transmitted diseases in humans. This obligate intracellular bacterium is biphasic; the intracellular

Address correspondence to Cho-chou Kuo, M.D., Ph.D., Department of Pathobiology, Box 357238, University of Washington, Seattle, Washington 98195-7238. Phone: 206-543-8689; FAX: 206-543-3873; E-mail: cckuo@u.washington.edu. S.Hakomori's present address is Pacific Northwest Research Foundation, Biomembrane Division, 720 Broadway, Seattle, Washington 98122; Y.O., Faculty of Science, Yokohama City University, Seto, Kanazawa-ku, Yokohama, Japan.

Received for publication 22 August 1996 and accepted in revised form 22 October 1996.

J. Clin. Invest.

(C) The American Society for Clinical Investigation, Inc.

0021-9738/96/12/2813/06 \$2.00

Volume 98, Number 12, December 1996, 2813-2818 form is the metabolically active reticulate body, and the extracellular form is the infectious elementary body $(\mathrm{EB})^{1}$ (1). A prominently exposed component on the surface of the chlamydial EB involved in the initial interaction between $C$. trachomatis and the host cell is the major outer membrane protein (MOMP; 40,000 $M_{\mathrm{r}}$ ) (2). The MOMP is the principal structural protein of the $\mathrm{EB}$, and its cross-linked disulfide bonds provide rigidity to the cell wall (3). The serological specificity of the organism resides in MOMP, and antibodies raised against MOMP neutralize infectivity of chlamydia $(4,5)$.

MOMP and two other chlamydial proteins $(32,000$ and $18,000 M_{\mathrm{r}}$ ) were identified as glycoproteins probed by various plant lectins (6). Further characterization showed these three proteins are glycosylated with an $\mathrm{N}$-linked carbohydrate $(7,8)$. It is the general belief that $\mathrm{N}$-linked structure is rarely present in bacteria (9). We demonstrated that the carbohydrate moieties of the MOMP are involved in the attachment process of C. trachomatis organisms to HeLa cells (10). Using lectin-binding assays and glycosidase treatments, the terminal carbohydrate may contain galactose, mannose, and $\mathrm{N}$-acetylglucosamine (7). Further determination of the carbohydrate structure of the MOMP has been extremely difficult because of the limited availability of purified $C$. trachomatis organisms and even greater scarcity of MOMP and other glycoproteins of the outer membrane. This difficulty has been overcome by use of the two-dimensional mapping technique using $\sim 100 \mathrm{pmol}$ of fluorescent-labeled carbohydrate released from $\mathrm{N}$-linked glycoprotein $(11,12)$. We now describe unequivocal presence of N-linked oligosaccharides associated with C. trachomatis MOMP, and the identification of specific structures in each separated fraction. The predominance of high-mannose type oligosaccharide in MOMP, and the inhibition of infectivity by both high-mannose type glycopeptide as well as high-mannose type oligosaccharide, indicate that these structures are involved in infectivity of $C$. trachomatis to HeLa cells.

\section{Methods}

Materials. Hypaque-76 was from Winthrop Laboratories (Sterling Drug Inc., New York, NY). Structurally defined oligosaccharides were from Oxford GlycoSystems (Rosedale, NY). Recombinant $N$-glycanase was from Genzyme Corp. (Boston, MA). Hen egg ovalbumin and pronase B were from Sigma Chemical Co. (St. Louis, MO). Concanavalin A (ConA)-Sepharose and Sephadex G-50 were from Pharmacia AB (Uppsala, Sweden). Tritiated-leucine was from DuPont NEN (Boston, MA). NCS tissue solubilizer and aqueous counting scintillant were from Amersham, Arlington Heights, IL. The pyridyl-

1. Abbreviations used in this paper: ConA, concanavalin A; EB, elementary body; MOMP, major outer membrane protein; ODS, octadecylsilyl. 
Table I. N-Linked Oligosaccharide Structures of the 40-kD Glycoprotein of Chlamydia trachomatis

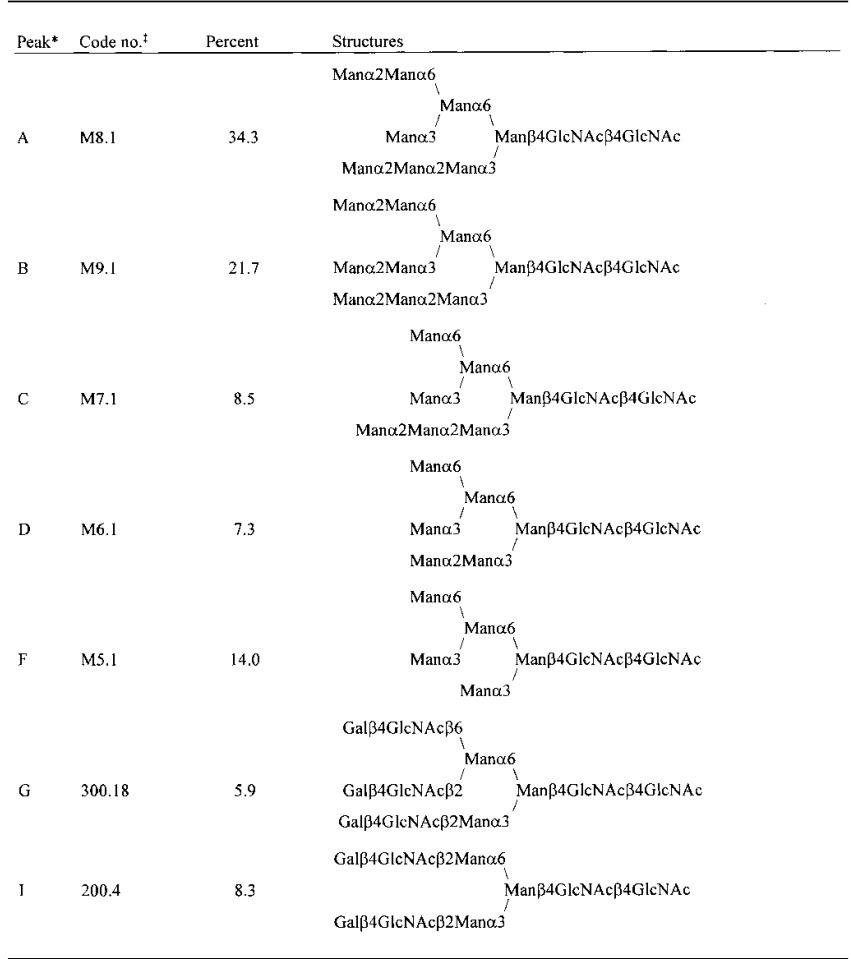

* The oligosaccharide structure of the corresponding peak from Fig. 1 is shown. ${ }^{\ddagger}$ Code no. cited are the same as previously defined (11).

amino derivatives of reference oligosaccharides (code no. M9.1, M8.1, M7.1, M7.2, M6.1, M5.1, H5.1, H4.3, H4.4, 200.4, 300.18, and 301.1) and isomalto-oligosaccharides (4-20 glucose residues) were from Nakano Vinegar Co. (Handa, Japan). The code number and corresponding reference oligosaccharides are given in Table I.

Organisms. Chlamydial strains used in this study were C. trachomatis $\mathrm{L}_{2} / 434 / \mathrm{Bu}$, C. pneumoniae AR-39, and C. psittaci $6 \mathrm{BC}$. The organisms were grown in HeLa 229 cells and purified by Hypaque gradient centrifugation (13). $250 \mathrm{mg}$ of purified organisms from 500 culture flasks of $112 \mathrm{~cm}^{2}$ size were used for preparation of the membrane glycoprotein.

Preparation of chlamydial glycan. The membrane glycoproteins were prepared from C. trachomatis $\mathrm{L}_{2} / 434 / \mathrm{Bu}$ as described previously (10). MOMP glycoprotein was separated from other proteins in a sodium dodecyl sulfate- $12.5 \%$ polyacrylamide gel. The $40-\mathrm{kD}$ band was excised, electroeluted from the gel, and stored at $-20^{\circ} \mathrm{C}$. The material was pooled and concentrated by centrifugation at $5,000 \mathrm{~g}$ at $4^{\circ} \mathrm{C}$ in an Ultrapure filter unit with an exclusion factor of a molecular weight of 10,000 (Millipore, Bedford, MA). The purity of 40-kD glycoprotein preparations was checked by sodium dodecylsulfate-polyacrylamide gel electrophoresis and immunoblotting against the MOMP specific monoclonal antibody as described previously (10). The isolated glycoprotein was delipidated by methanol-chloroform fractionation according to Finne and Krusius (14). $3 \mathrm{mg}$ of isolated glycoprotein were digested with $\mathrm{N}$-glycanase digestion as previously described (10). Briefly, glycan was released from the glycoprotein by incubation for $48 \mathrm{~h}$ at $37^{\circ} \mathrm{C}$ with $0.3 \mathrm{U}$ of $\mathrm{N}$-glycanase. The enzyme reaction was stopped by boiling for $5 \mathrm{~min}$. After addition of three volumes of icecold $95 \%$ ethanol, the mixture was centrifuged at 5,000 $\mathrm{g}$ for $10 \mathrm{~min}$. The pellet was washed with $75 \%$ ethanol and centrifuged again. The first and second supernatants were combined and dried under nitrogen stream. The residue was used for structural analysis as described in the following section. This method usually yields $80-90 \%$ of carbo- hydrate from glycoproteins by measurement with orcinol-sulfuric acid $(11,12)$.

Determination of carbohydrate structure. Determination of N-linked oligosaccharide structures was performed by the two-dimensional sugar mapping technique developed by Tomiya et al. (11) and described by Takahashi and Tomiya (12). In this procedure, the oligosaccharides released were first pyridylaminated in the presence of sodium cyanoborohydride and then subjected to sequential high performance liquid chromatography (HPLC), first with a reverse phase octadecylsilyl (ODS)-silica column and then with an amide-silica column. 1/20th of the prepared pyridylaminated oligosaccharides were used each time for application to ODS column.

Preparation of ovalbumin glycopeptides. Glycopeptides from hen egg ovalbumin were separated into fractions containing hybrid type and high-mannose type carbohydrate using a ConA-Sepharose column (15). Briefly, $100 \mathrm{mg}$ of ovalbumin was dissolved in $10 \mathrm{ml}$ of 100 $\mathrm{mM}$ sodium bicarbonate buffer (buffer $\mathrm{A}$ ), passed through a ConASepharose column $(5 \mathrm{ml})$, and washed with 10 column volumes of buffer A. Ovalbumin containing hybrid type structure was eluted with $15 \mathrm{mM} \alpha$-methyl-glucoside in buffer A (fraction 1), and that containing high-mannose type was eluted with $200 \mathrm{mM} \alpha$-methyl-mannoside in buffer $\mathrm{A}$ (fraction 2). Fractions 1 and 2 were dialyzed against distilled water, concentrated to a volume of $2 \mathrm{ml}$ to which $8 \mathrm{mg}$ pronase $\mathrm{B}, 10 \mathrm{mM} \mathrm{CaCl}, 0.02 \%$ sodium azide in $0.1 \mathrm{M}$ sodium borate buffer ( $\mathrm{pH} 8.0)$ were added and digested for $2 \mathrm{~d}$. The digested material was evaporated to $1 \mathrm{ml}$ and fractionated on a Sephadex G-50 column $(1.5 \times 50 \mathrm{~cm})$. Sugar-containing fractions (monitored by phenolsulfuric acid reaction) were collected and lyophylized.

Inhibition of cell culture infectivity by ovalbumin glycopeptides and defined oligosaccharides. Two methods of assaying inhibition of cell culture infectivity by ovalbumin glycopeptides or defined oligosaccharides were performed using HeLa 229 cell monolayers grown in 96-well microtiter plates (16). One was the pretreatment of organisms with sugars, then inoculation onto HeLa cells. The other method was treatment of HeLa cells with sugars before inoculation. In both methods ovalbumin glycopeptides were tested in four-fold dilutions from 25 to $0.098 \mu \mathrm{g} / \mathrm{well}$. Defined oligosaccharides were tested at 20,5 , and $1.25 \mu \mathrm{g} /$ well.

For the assays in which the organisms were pretreated with a sugar, equal volumes of $90 \mu \mathrm{l}$ of each glycoconjugate dilution and $2 \times$ $10^{4}$ inclusion forming units $/ \mathrm{ml}$ of organism suspensions were mixed in a microtiter well and incubated at $35^{\circ} \mathrm{C}$ for $30 \mathrm{~min} .50 \mu \mathrm{l}$ of glycoconjugate/organism mixture were inoculated onto HeLa cell monolayers in duplicate and absorbed at $35^{\circ} \mathrm{C}$ for $2 \mathrm{~h}$ on a rocker platform. Inocula were then removed and the monolayers were washed with HBSS. Culture medium was added to wells, and the plates were sealed with parafilm and incubated at $35^{\circ} \mathrm{C}$ for $72 \mathrm{~h}$. Infectivity was assayed by counting inclusions that were stained by immunofluorescence using the fluorescein isothiocyanate-conjugated chlamydia genus-specific monoclonal antibody, CF-2, prepared in our laboratory. Positive controls included monoclonal antibodies 155-35 and RR-402 which neutralize infectivity of $\mathrm{L}_{2}$ and AR-39, respectively. Monoclonal antibody KK-12 which does not have neutralizing activity was used as the negative control. These monoclonal antibodies have been described previously $(5,10,17)$. A reduction of more than $50 \%$ of inclusion counts is regarded as indicating positive neutralization for chlamydia (16).

For the experiments in which HeLa cells were pretreated with a sugar, $50 \mu \mathrm{l}$ of diluted glycoconjugate were added to the well of HeLa cell monolayer in duplicate. The plate was incubated at $35^{\circ} \mathrm{C}$ for 30 min. After removal of the glycoconjugate, the monolayers were washed with HBSS. The inocula were added onto the pretreated $\mathrm{HeLa}$ cell monolayers and absorbed at $35^{\circ} \mathrm{C}$ for $2 \mathrm{~h}$. The protocol as mentioned above was then followed.

Radiolabeling of chlamydial organisms. Chlamydial organisms were metabolically labeled by culturing with low leucine (1/10 of the normal concentration)-Eagle's minimum essential medium containing $50 \mu \mathrm{Ci}$ of $\left[{ }^{3} \mathrm{H}\right]$ leucine per $112 \mathrm{~cm}^{2}$ flask in the presence of $0.8 \mu \mathrm{g} / \mathrm{ml}$ 
cycloheximide (18). Tritium-labeled organisms were purified by centrifugation through a cushion of $30 \%$ Hypaque-76, and resuspended in phosphate buffered saline (PBS). An aliquot was used for preparation of formalin-fixed organisms by addition of $0.02 \%$ formalin (final concentration) and incubated at $4^{\circ} \mathrm{C}$ for $72 \mathrm{~h}$. Formalin was removed by centrifugation and washing organisms once with PBS.

Attachment of tritiated chlamydial organisms to HeLa cells and its inhibition by ovalbumin glycopeptides. Inhibition of attachment of tritiated chlamydial organisms to HeLa cell monolayers grown in culture vials was assayed as described previously (18). Both live and formalin-fixed organisms were tested. Serial fourfold dilutions of ovalbumin glycopeptides were mixed with organisms and incubated at room temperature for $30 \mathrm{~min}$. Glycopeptide/organism mixtures were inoculated onto HeLa cell monolayers in duplicate and incubated at $4^{\circ} \mathrm{C}$ for $30 \mathrm{~min}$. Inocula were removed and cell monolayers were washed three times with PBS. One $\mathrm{ml}$ of tissue solubilizer was added per vial and incubated at room temperature overnight. Digested tissue suspension was dissolved in $10 \mathrm{ml}$ of scintillation fluid and the radioactivity counted in a scintillation counter (LS-5800 series, Liquid Scintillation System; Beckman Instrument, Inc., Palo Alto, CA).

\section{Results}

Oligosaccharide structure of 40-kD MOMP glycoprotein. 10 fluorescent-labeled oligosaccharide peaks were separated by HPLC (peaks A to J in Fig. 1). Peaks A to F comprised about $80 \%$ of the total oligosaccharides. Peaks A through D and F

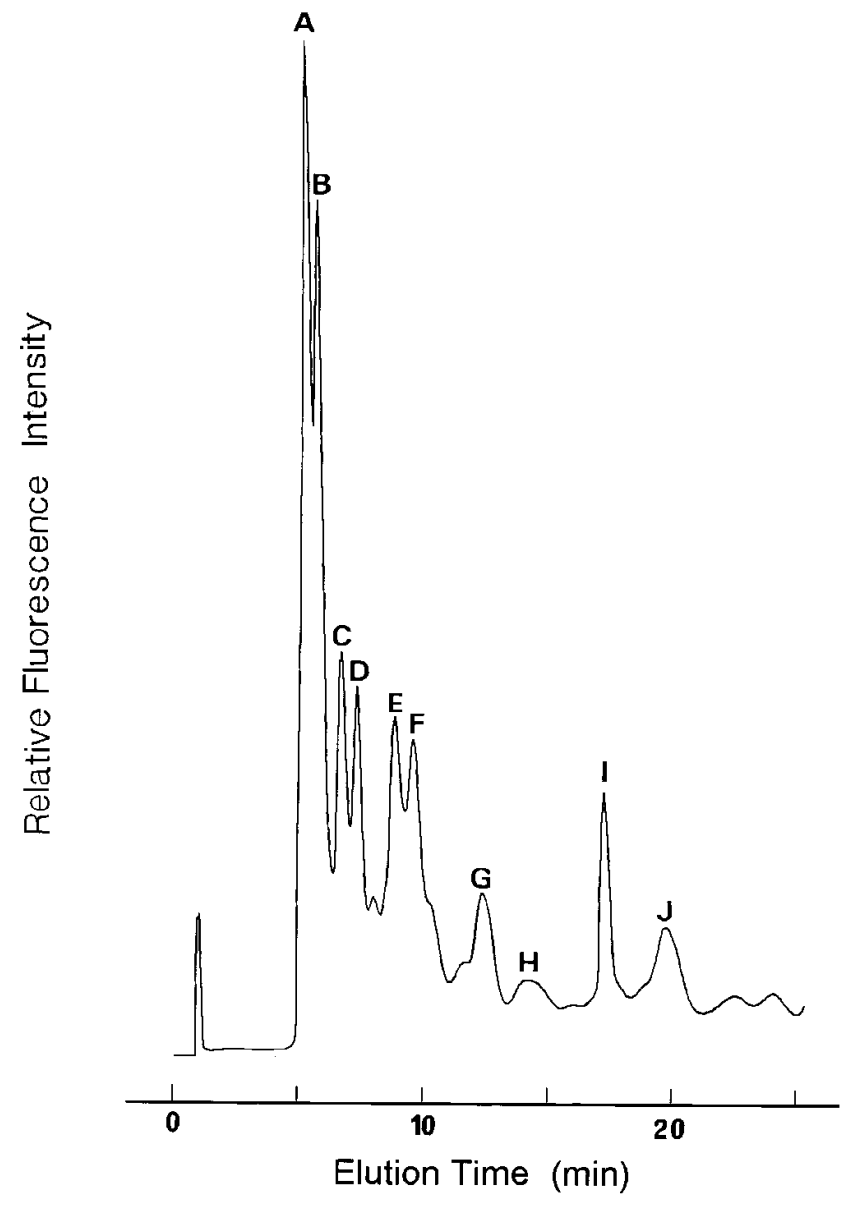

Figure 1. Chromatography of pyridylaminated-oligosaccharides of the glycan from the 40-kD MOMP glycoprotein. The oligosaccharide structure in each peak is given in Table I.
Table II. Oligosaccharide Compositions of Ovalbumin Fractionated by Concanavalin A-Sepharose Column

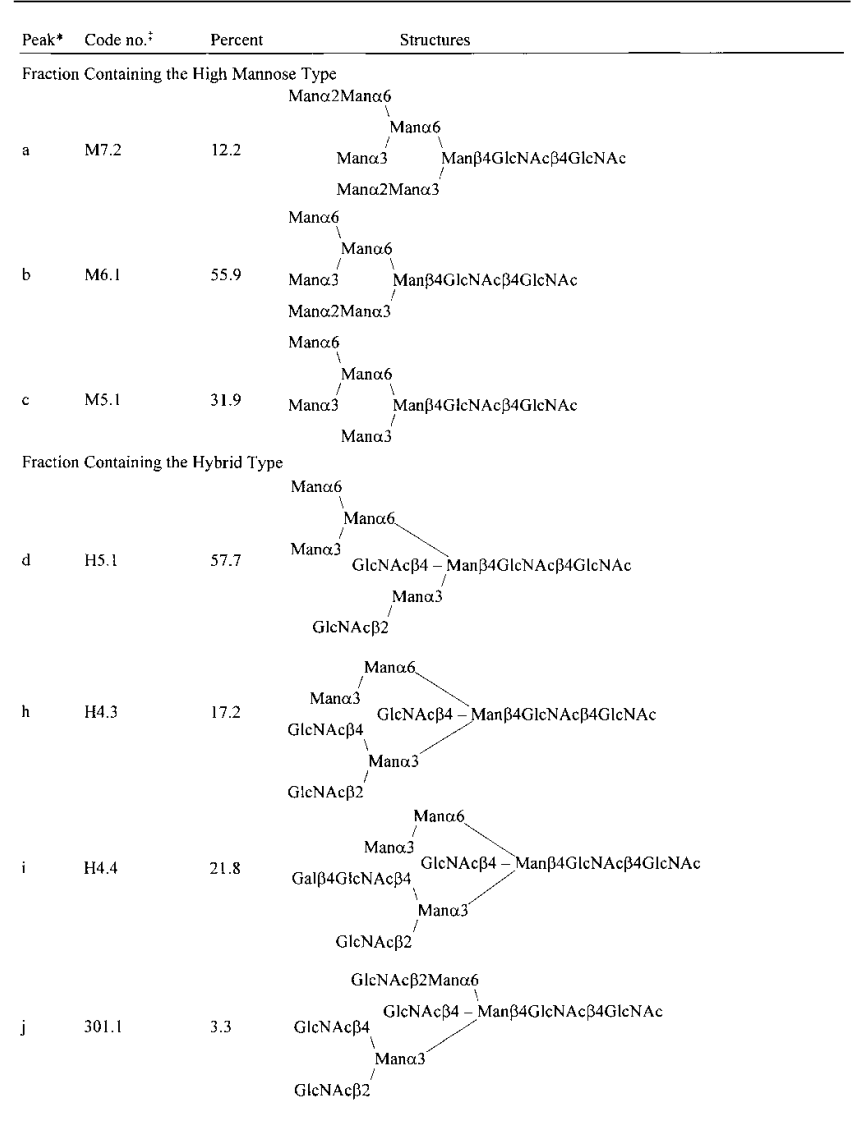

* The peaks a through $\mathrm{j}$ correspond to those reported previously (11, 12). ${ }^{\ddagger}$ Code no. cited are the same as previously defined (11).

were identified as high-mannose types by two-dimensional sugar mapping as shown in Table I. Peaks G and I were identified as a triantennary and a biantennary oligosaccharide, respectively, that contained terminal galactose (Table I). Peaks E, $\mathrm{H}$, and $\mathrm{J}$, and other minor peaks were not identified because the quantity was not sufficient. The oligosaccharides were $\mathrm{N}$-linked. No sialic acid was detected. No galactosamine and N-acetylgalactosamine were found on sugar analysis, suggesting the absence of O-linked oligosaccharides. Previous studies also showed the $40-\mathrm{kD}$ glycoprotein was not affected by endo- $\alpha-\mathrm{N}$-acetylgalactosaminidase, which is specific to O-linked glycans (7).

Oligosaccharide structures of ovalbumin glycopeptides. Seven fluorescent-labeled oligosaccharide peaks were separated in two-dimensional sugar mapping. Three of the peaks present in fraction 2 from the ConA column were identified as highmannose type (peaks a to $\mathrm{c}$ in Table II). Oligosaccharides present in fraction 1 from the ConA column were identified as hybrid type (peaks d to $\mathrm{j}$ in Table II). These structures have been determined previously $(11,12)$.

Inhibition of infectivity of chlamydial organisms to HeLa cells by high-mannose versus hybrid type glycopeptides. We previously reported that the carbohydrate moiety of the $40-\mathrm{kD}$ MOMP is a ligand involved in attachment of the chlamydial EB to the host cell (10). Structural analysis now revealed that the major component of the MOMP oligosaccharide is high- 

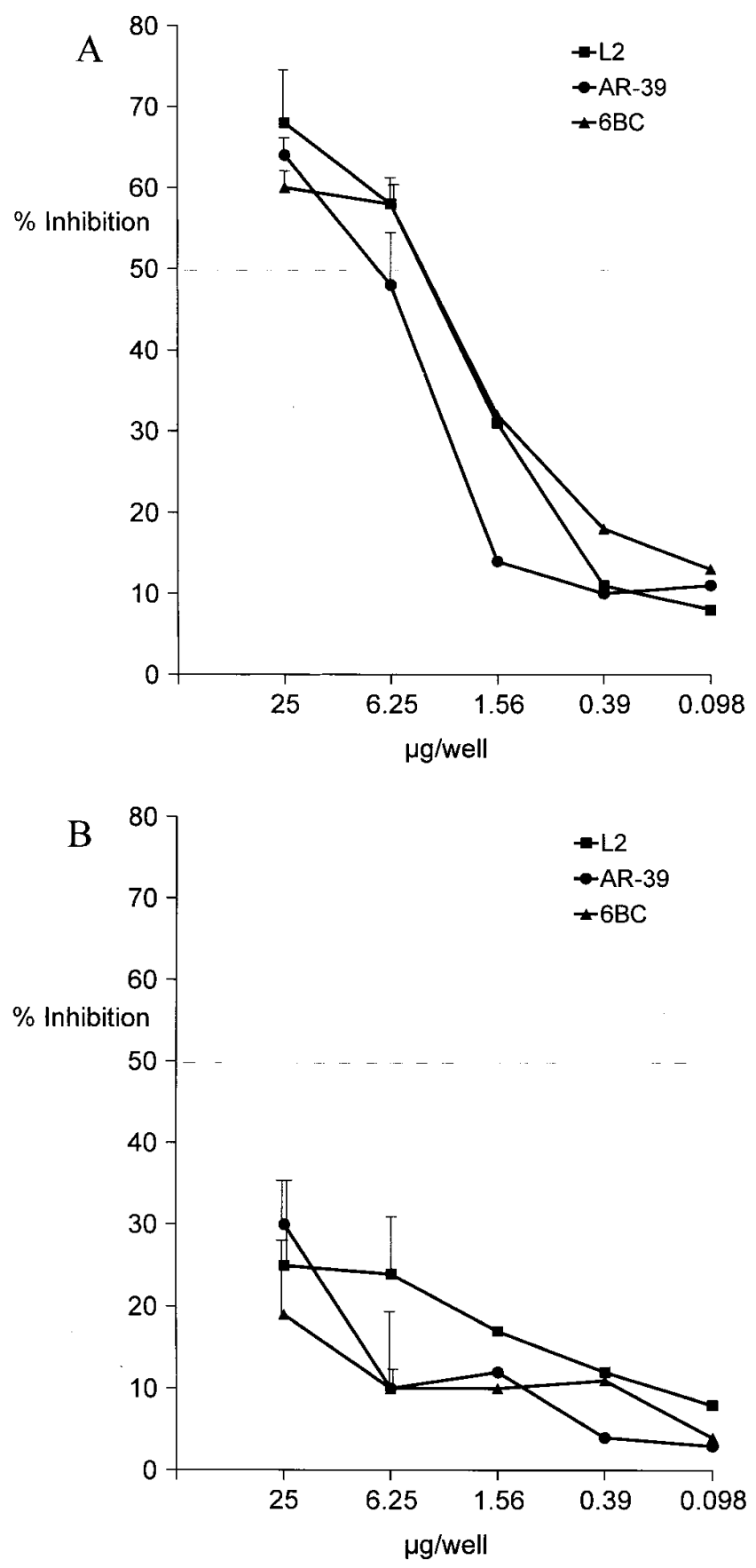

Figure 2. Inhibition of infectivity of Chlamydia species in HeLa cells with glycopeptides from hen ovalbumin. Ovalbumin was fractionated into high-mannose $(A)$ and hybrid $(B)$ type glycopeptides by a ConA column. A fourfold dilution of glycopeptides was mixed with an organism suspension, incubated at $35^{\circ} \mathrm{C}$ for $30 \mathrm{~min}$, and inoculated onto HeLa cell monolayers in duplicate. Inhibitory effects of glycopeptides were assayed by inclusion counts with fluorescent antibody staining of $3 \mathrm{~d}$ cultures. Strains tested were Chlamydia trachomatis $\mathrm{L}_{2} / 434 / \mathrm{Bu}$, Chlamydia pneumoniae AR-39, and Chlamydia psittaci 6BC. Each point is the average of two experiments. Bar indicates the distance of each observation from the average. Positive and negative controls using neutralizing and non-neutralizing monoclonal antibodies reacted appropriately (data not shown). A reduction of more than $50 \%$ of inclusion counts in comparison to cultures inoculated with organism alone is regarded as positive neutralization for chlamydia (16). mannose type and the minor components are complex type. It is extremely difficult to isolate sufficient quantities of native oligosaccharides from chlamydial organisms for functional studies. Because fractions 1 and 2 of hen egg ovalbumin contain oligosaccharides with the similar structure to that of the MOMP glycoprotein and are readily available, we used them to determine which oligosaccharides are effective in inhibiting infectivity of chlamydial organisms to HeLa cells. In the experiments in which organisms were incubated with glycopeptides before inoculation, fraction 2, which contained high-mannose type oligosaccharides (Table II), inhibited infectivity (Fig. 2 $A)$. There was greater than $50 \%$ inhibition in inclusion counts from 25 to $6.25 \mu \mathrm{g} / \mathrm{ml}$ concentrations. In contrast, fraction 1 which contained oligosaccharides of hybrid type (Table II) did not inhibit at least $50 \%$ of infectivity at any concentrations tested (Fig. $2 \mathrm{~B}$ ). Testing of ovalbumin showed inhibition at greater than $100 \mathrm{mg} / \mathrm{ml}$ concentrations. The positive and negative controls with monoclonal antibodies reacted appropriately. All species of chlamydia, represented by $\mathrm{L}_{2}, \mathrm{AR}-39$, and 6BC strains, were equally inhibited by high-mannose type oligosaccharides (Fig. $2 \mathrm{~A}$ ). Pretreatments of HeLa cells with glycopeptides gave similar results. Percent inhibitions for three concentrations of glycopeptides $(25,6.25$, and $1.56 \mu \mathrm{g})$ in repeated tests were, respectively, $(63,66),(52,50)$, and $(34,33)$ for high-mannose glycopeptides, and $(35,29),(31,20)$, and $(31$, 15) for hybrid-type glycopeptides.

Inhibition of attachment of C. trachomatis to HeLa cells by high-mannose versus hybrid type glycopeptides. Because the fraction containing the high-mannose type oligosaccharides inhibited infectivity, we determined whether inhibition was due to the blocking of attachment. High-mannose glycopeptides inhibited attachment of live organisms effectively at 25 to 6.25 $\mu \mathrm{g} / \mathrm{ml}$ concentrations, which paralleled the inhibition of infectivity (Fig. $3 \mathrm{~A}$ ). Attachment of formalin-fixed organisms was also inhibited by high-mannose glycopeptides but to a greater degree $(25-1.56 \mu \mathrm{g} / \mathrm{ml})$ (Fig. $3 A$ ). This may be due to the denaturation by formalin of proteinous ligands involved in attachment. The blocking of attachment of formalin-fixed organisms showed that inhibition was specific to the carbohydrate moiety. The fraction containing the hybrid type oligosaccharides did not prevent attachment of either live or formalinfixed organisms (Fig. $3 \mathrm{~B}$ ).

Inhibition of infectivity of C. trachomatis to HeLa cells by structurally defined oligosaccharides. Based on the above observations with glycopeptides, we next analyzed the infectivityinhibitory effects of pure defined high-mannose type oligosaccharides with different structures and different numbers of mannose residues. These effects were compared with those of complex and hybrid type oligosaccharides. In the experiments in which organisms were preincubated with sugars for inoculation of HeLa cells, significant inhibition was seen at $20 \mu \mathrm{g}$ for each oligomer. Oligosaccharides of Man-8 D1,D3, which had a structure similar to peak A from MOMP (Fig. 1 and Table I), demonstrated the strongest inhibitory effect on infectivity followed by Man-9, then Man-6, and Man-7, in that order (Table III), which had structures similar to peaks B, D, and C, respectively. The tri- and bi-antennary structures corresponding to peaks $\mathrm{G}$ and I, respectively, had similar activity to Man-6 and -7; conserved trimannose core structure had minimal activity. Oligosaccharides not found in chlamydial glycan including the isomer of Man-8 and di-sialylated-, galactosylated biantennary oligosaccharide were also tested. Only the high-mannose 

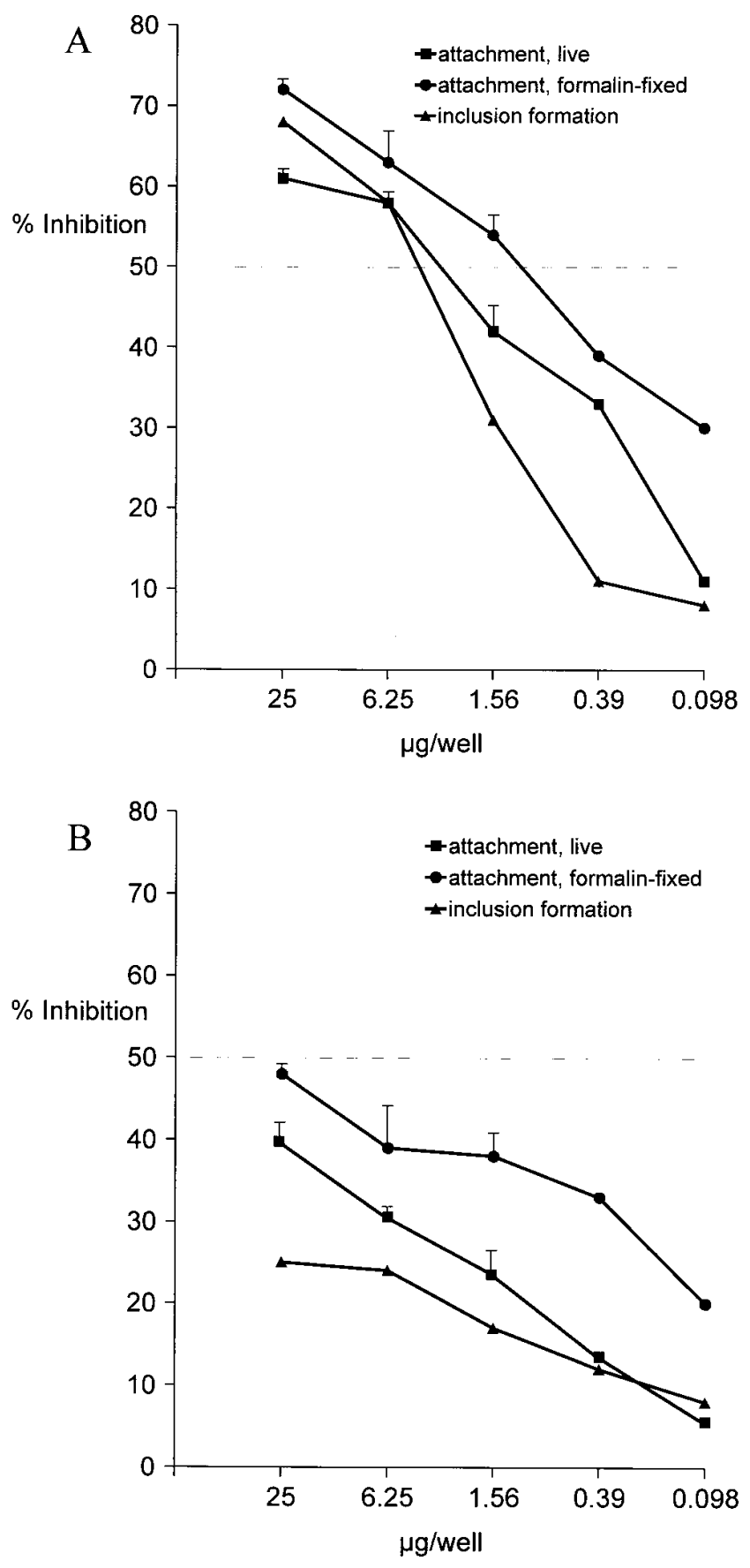

Figure 3. Inhibition of attachment of Chlamydia trachomatis $\mathrm{L}_{2} / 434 /$ $\mathrm{Bu}$ to HeLa cells with glycopeptides from hen ovalbumin. Experiments using the high-mannose type glycopeptides are shown in $A$, and the hybrid-type glycopeptides are in $B$. Tritium-labeled organisms, either live or formalin-fixed, were mixed with fourfold dilutions of glycopeptides, incubated at room temperature for $30 \mathrm{~min}$, inoculated onto HeLa cell monolayers in duplicate, and absorbed at $4^{\circ} \mathrm{C}$ for $30 \mathrm{~min}$. Inocula were removed, cell monolayers washed, and the radioactivity associated with cells counted. Each data point is an average of two experiments. Bar indicates the distance of each observation from the average. Also shown for comparison are the inclusion counts in experiments from Fig. 2.
Table III. Infectivity Inhibition with Oligosaccharides

\begin{tabular}{lcc}
\hline \multicolumn{1}{c}{ Oligosaccharides } & Peak* & $\begin{array}{c}\text { Percentage } \\
\text { inhibition }^{*}\end{array}$ \\
\hline Oligomannose 9 & B & 64,62 \\
Oligomannose 8 D1,D3 & A & 74,75 \\
Oligomannose 8 (isomer) & $(-)^{\S}$ & 55,56 \\
Oligomannose 7 D3 & C & 46,49 \\
Oligomannose 6 & D & 54,54 \\
Asialo-, galactosylated triantennary & G & 50,46 \\
Asialo-, galactosylated biantennary & I & 45,42 \\
Di-sialylated-, galactosylated biantennary & $(-)$ & 20,34 \\
Conserved trimannosyl core & $($ core) & 26,29 \\
& &
\end{tabular}

* See Fig. 1 and Table I for structures. ${ }^{\ddagger}$ Percent inhibition shows two separate sets of experiments at the maximum concentration $(20 \mu \mathrm{g})$ tested. ${ }^{\S}(-)$ sign indicates structures not found in chlamydia. ${ }^{\|}$(core) indicates the core structure of chlamydial oligosaccharides.

type showed a weak inhibitory effect. Pretreatment of HeLa cells with high-mannose type oligosaccharides also inhibited infectivity effectively. Percent inhibitions for three oligosaccharides tested at 20,5 , and $1.25 \mu \mathrm{g}$ in repeated tests were, respectively, $(67,77),(54,50)$, and $(40,32)$ for mannose- 8 D1,D3; $(59,60),(43,40)$, and $(26,19)$ for mannose-9; and $(44$, $49),(32,36)$; and $(29,37)$ for conserved trimannosyl core.

\section{Discussion}

Our previous studies indicate that the carbohydrate moiety of the 40-kD MOMP and other glycoproteins expressed on chlamydial organisms is involved in attachment and infectivity (10). The carbohydrate moiety of MOMP binds ConA, wheat germ agglutinin, and Dolichos biflorus agglutinin; but not to lectins from Ulex europaeus agglutinin, soybean agglutinin or Ricinus communis agglutinin. Binding to wheat germ agglutinin is not affected by sialic acid in the hapten inhibition assay or treatment with sialidase, indicating the carbohydrate contains only $\mathrm{N}$-acetylglucosamine. This finding reaffirms that the glycan is chlamydial and not of HeLa cell origin because the HeLa cell membrane is rich in sialic acid. The presence of $\mathrm{N}$-linked GlcNAc susceptible to endoglycanase $\mathrm{F}$ in the MOMP is confirmed in this study. Novel N-linked GalNAc and $\mathrm{N}$-linked Glc in addition to N-linked GlcNAc were found in glycoproteins of Halobacterium halobium. The former two linkages were insusceptible to endoglycanase F (9). N-linked carbohydrate is common in eukaryotic glycoproteins, but is extremely limited in prokaryotic glycoproteins. However, MOMP cannot be derived from host cell glycoprotein because MOMP is a specific chlamydial product. The lectin-binding properties of MOMP and its susceptibility to glycosidase indicate that MOMP glycoprotein contains $\alpha$-Man and $\beta$-GlcNAc at the terminus.

An unambiguous structural determination of the $40-\mathrm{kD}$ MOMP and other glycoproteins is essential for understanding the biological function of carbohydrates in the infection process of chlamydial organisms. Application of a highly sensitive two-dimensional sugar mapping technique developed by Takahashi and her colleagues $(11,12)$ enabled us to identify the major oligosaccharide expressed on the 40-kD MOMP glycoprotein as the high-mannose type and the minor oligosaccha- 
ride as the complex type. These findings made possible a new approach for testing whether high-mannose type glycopeptides or oligosaccharides inhibit attachment and infectivity of chlamydial organisms to host cells, e.g., HeLa cells.

The important findings and indications that high-mannose type oligosaccharides are involved in attachment and infectivity of C. trachomatis, C. pneumoniae, and C. psittaci to HeLa cells were: (a) Glycopeptides having high-mannose type showed much stronger inhibition of infectivity of all three chlamydial species in comparison to those having hybrid type; (b) The same trend was observed for inhibition of attachment of live and formalin-fixed C. trachomatis organisms, in parallel to the above results for infectivity inhibition; and (c) Highmannose type oligosaccharides having 8 mannose residues with a defined structure showed a stronger inhibitory effect on infectivity than those having 7 or 9 mannose residues.

Thus, the high-mannose type oligosaccharides expressed on the MOMP glycoprotein at the outer membrane surface of chlamydial organisms appear to play essential roles in attachment and entry (infectivity) of organisms to host cells. The molecule that recognizes chlamydial MOMP oligosaccharides present on host cells, i.e., HeLa cells, is not yet identified. It may be an analog of the mannose-binding proteins which are widely distributed on mammalian cells and have been well characterized (19).

High-mannose containing glycopeptides from ovalbumin inhibited the attachment and infectivity of chlamydial organisms to HeLa cells. This finding confirmed our observation in 1973 that ovalbumin inhibits the infectivity of $C$. trachomatis to HeLa cells (20). In contrast to antibody neutralization, infectivity inhibition by high-mannose type oligosaccharides is not strain specific. Further studies on infectivity inhibition by oligosaccharide analogs should enhance our understanding of the molecular mechanism of chlamydial pathogenesis, and also lead to development of effective measures for prevention and treatment of chlamydial infection.

\section{Acknowledgments}

This study was supported in part by grants EY-00219 and CA-42505 from the National Institutes of Health.

\section{References}

1. Moulder, J.W., T.P. Hatch, C.-C. Kuo, J. Schachter, and J. Storz. 1984. Chlamydia Jones, Rake, and Stearn 1945, 55. In Bergey's Manual of Systemic
Bacteriology. Vol. 1. N.R. Krieg, editor. Williams \& Wilkins, Baltimore. 729 735 .

2. Caldwell, H.D., and R. Judd. 1982. Structural analysis of chlamydial major outer membrane protein. Infect. Immun. 38:960-968.

3. Newhall, W.J., V, and R.B. Jones. 1983. Disulfide-linked oligomers of the major outer membrane protein of chlamydiae. J. Bacteriol. 154:998-1001.

4. Caldwell, H.D., and L.J. Perry. 1982. Neutralization of Chlamydia trachomatis infectivity with antibodies to the major outer membrane protein. Infect. Immun. 38:745-754.

5. Lucero, M.E., and C.-C. Kuo. 1985. Neutralization of Chlamydia trachomatis cell culture infection by serovar-specific monoclonal antibodies. Infect. Immun. 50:595-597.

6. Swanson, A.F., and C.-C. Kuo. 1990. Identification of lectin-binding proteins in Chlamydia species. Infect. Immun. 58:502-507.

7. Swanson, A.F., and C.-C. Kuo. 1991. Evidence that the major outer membrane protein of Chlamydia trachomatis is glycosylated. Infect. Immun. 59: 2120-2125.

8. Swanson, A.F., and C.-C. Kuo. 1991. The characterization of lectin-binding proteins of Chlamydia trachomatis as glycoproteins. Microb. Pathog. 10: 465-473.

9. Wieland, F. 1988. Structure and biosynthesis of prokaryocytic glycoproteins. Biochimie (Paris). 70:1493-1504.

10. Swanson, A.F., and C.-C. Kuo. 1994. Binding of the glycan of the major outer membrane protein of Chlamydia trachomatis to HeLa cells. Infect. Immun. 62:24-28.

11. Tomiya, N., J. Awaya, M. Kurono, S. Endo, Y. Arata, and N. Takahashi. 1988. Analyses of N-linked oligosaccharides using a two-dimensional mapping technique. Anal. Biochem. 171:73-90.

12. Takahashi, N., and N. Tomiya. 1992. Chapter 8. Analysis of N-linked oligosaccharides: Application of glycosaminidase A. In Handbook of Endoglycosidases and Glycosaminidase. N. Takahashi and T. Muramatsu, editors. CRC Press, Boca Raton, FL. 183-332.

13. Kuo, C.-C., S.-P. Wang, and J.T. Grayston. 1977. Growth of trachoma organism in HeLa 229 cell culture. In Nongonococcal urethritis and related infections, D. Hobson and K.K. Holmes, editors. American Society for Microbiology, Washington, D.C. 328-336.

14. Finne, J., and T. Krusius. 1982. Complex carbohydrates. D. Preparation and fractionation of glycopeptides. In Methods in Enzymology. Academic Press, New York. 83:269-277.

15. Krusius, T., J. Finne, and H. Rauvala. 1976. The structural basis of the different affinities of two type of acidic N-glycosidic glycopeptides for concanavalin A-Sepharose. FEBS Lett. 71:117-120.

16. Byrne, G.I., R.S. Stephens, G. Ada, H.D. Caldwell, H. Su, R.P. Morrison, B. Van Der Pol, P. Bavoil, L. Bobo, S. Everson et al. 1993. Workshop on in vitro neutralization of Chlamydia trachomatis: summary of proceedings. J. Infect. Dis. 168:415-420.

17. Puolakkainen, M., J. Parker, C.-C. Kuo, J.T. Grayston, and L.A. Campbell. 1995. Further characterization of Chlamydia pneumoniae specific monoclonal antibodies. Microbiol. Immunol. 39:551-554.

18. Kuo, C.-C., and J.T. Grayston. 1976. Interaction of Chlamydia trachomatis organisms and HeLa 229 cells. Infect. Immun. 13:1103-1109.

19. Taylor, M.E., J.T. Conary, M.R. Lennart, P.D. Stahl, and K. Drickamer. 1990. Primary structure of the mannose receptor contains multiple motifs resembling carbohydrate-recognition domains. J. Biol. Chem. 265:12156-12162.

20. Kuo, C.-C., S.-P. Wang, and J.T. Grayston. 1973. Effect of polycations, polyanions, and neuraminidase on the infectivity of trachoma-inclusion conjunctivitis and lymphogranuloma venereum organisms in HeLa cells: sialic acid residues as possible receptors for trachoma-inclusion conjunctivitis. Infect. Immun. 8:74-79. 